\title{
Helvella hyperborea and $H$. pedunculata found in North America
}

\author{
HARRI HARMAJA
}

\begin{abstract}
HARMAJA, H. 1981: Helvella hyperborea and H. pedunculata found in North America. - Karstenia 21: 49.

The author reports one collection of Helvella hyperborea Harmaja (sect. Acetabulum Diss.) and five collections of $H$. pedunculata Harmaja (sect. Leucomelaenae Diss.) from inner Quebec, Canada. The recently described species have been known only from northwestern Europe.
\end{abstract}

Harri Harmaja, Botanical Museum, University of Helsinki, Unioninkatu 44, SF-00170 Helsinki 17, Finland

\begin{abstract}
Among fungi collected in Quebec by Finnish mycologists from Turku University and sent to me for identification, I detected one immature specimen of Helvella hyperborea Harmaja (sect. Acetabulum Diss.) and five specimens of $H$. pedunculata Harmaja (sect. Leucomelaenae Diss.). Both species were described only recently (Harmaja 1978) and treated more comprehensively in a paper published in the following year (Harmaja 1979). H. hyperborea was known from Finland, Sweden, Norway and Iceland, and $H$. pedunculata from Finland and Norway, so the present records add a new continent and a new country to their distribution areas. However, the species have presumably been collected in additional areas but been misnamed or not named at all. For example, 'H. solitaria (Karst.) Karst.' as treated by Kempton and Wells
\end{abstract}

(1970) may include specimens of $H$. pedunculata.

\section{Specimens examined}

\section{H. hyperborea}

Canada. Quebec. New Quebec Terr.: SE of Schefferville, N end of Astray Lake, SE of Mike Lake, $54^{\circ} 41^{\prime} \mathrm{N} / 66^{\circ} 37^{\prime} \mathrm{W}$, alt. $1700 \mathrm{ft}$., brook flowing to Astray Lake below the road, 4. VIII. 1967 Mäkinen 67-1371 (TUR).

\section{H. pedunculata}

Canada. Quebec. New Quebec Terr.: SE of Schefferville, N end of Astray Lake, SE of Mike Lake, $54^{\circ} 41^{\prime} \mathrm{N} / 66^{\circ} 37^{\prime} \mathrm{W}$, alt. $1700 \mathrm{ft}$., brook flowing to Astray Lake below the road, 4. VIII. 1967 Heikkilä (TUR); Mäkinen 67-1370 (TUR); Mäkinen 67-1373 (TUR); Kallio (TUR). Schefferville, area between the SE ends of John Lake and Dolly Lake, on a floating Philonotis carpet of a spring, 28. VII. 1978 Kallio \& Mäkinen (TUR).

\section{References}

Harmaja, H. 1978: New species and combinations in Helvella and Gyromitra. - Karstenia 18: 57.

- 1979: Studies on cupulate species of Helvella. - Karstenia 19: $33-45$.

Kempton, P. E. \& Wells, V. L. 1970: Studies on the fleshy fungi of Alaska 4. A preliminary account of the genus Helvella. - Mycologia 62: 940-959.

Accepted for publication on March 24, 1981 